\title{
Otolaryngology Surgical Activity in Tertiary Care Center During the Covid-19 Lockdown
}

\author{
Balasubramanyam Atru $^{1} \cdot$ Mithun Sutrave $^{1}$ (D) Rani George $^{1} \cdot$ Rhea James $^{1} \cdot$ \\ Anita Ross ${ }^{1} \cdot$ Pratibha C.B $^{1}$
}

Received: 27 July 2020/Accepted: 14 September 2020/Published online: 1 October 2020

(C) Association of Otolaryngologists of India 2020

\begin{abstract}
Corona virus disease (COVID 19) is an infectious respiratory disease caused by the novel virus severe acute respiratory syndrome coronavirus 2 (SARS-CoV-2). With many countries implementing lockdown the surgical activities in the division of otolaryngology across the world has been affected with many hospital confining themselves to only emergency or essential surgeries. The aim of this work is to report and discuss the in the surgical activity of the otolaryngology unit of the St John's National Academy of Health Sciences, Bangalore (India) during the pandemic. We performed acute and subacute emergencies which include diagnosis and treatment of malignant tumors of the head and neck, management of airway emergencies in adults and children, drainage of abscesses of the head and neck, Foreign body removal, emergency nasal debridement and surgeries for the unsafe ear. With the pandemic the surgical activities in otolaryngology changed drastically and with strict protocol and triaging put in place the risk for Health care workers was avoided and services to patients delivered.
\end{abstract}

Keywords COVID 19 - Aerosol generating procedure . Tracheostomy $\cdot$ Triage

Mithun Sutrave

mithunsutrave87@gmail.com

1 Department of ENT, St John's National Academy of Health Sciences, Sarjapur Road, Bangalore, Karnataka 560034, India

\section{Introduction}

Corona virus disease (COVID 19) is an infectious respiratory disease caused by the novel virus severe acute respiratory syndrome coronavirus 2 (SARS-CoV-2).

Initially a zoonotic disease it lead to human to human transmission through droplets which later became a world wide pandemic [1].

As it is a respiratory disease and with evidence of viral load in the upper airway and the symptomatology pattern over lapping with that of common illnesses and most being asymptomatic carriers the otolaryngologist are at risk while performing surgeries of the upper airway which involves high aerosol generation and exposure [2, 3].

With many countries implementing lockdown the surgical activities in the division of otolaryngology across the world has been affected with many hospital confining themselves to only emergency or essential surgeries.

The lockdown in India was announce from 25/3/2020 to 20/5/2020.

With directions and recommendation from government bodies, national and international organisation, and hospital committees the selection criteria for the surgeries were drafted and followed to reduce the exposure to health care professionals.

Our hospital being a tertiary care referral centre in southern India has wide array of cases coming from various parts and due to the pandemic the activity of our otolaryngology unit underwent profound changes still ensuring the diagnostic and therapeutic procedures by strictly complying to the directives. 


\section{Aims and Objectives}

The aim of this work is to report and discuss the in the surgical activity of the otolaryngology unit of the St John's National Academy of Health Sciences, Bangalore (India) during the pandemic. Particular attention was given to the number of procedures and type of surgery performed during the pandemic, and data were compared with the same period in 2019.

\section{Methodology}

A triage system was followed for the surgeries which is based on the need of performing the procedure, risk involved and type of protection required by the health care worker. The various categories of surgeries are highlighted in Table 1.

\section{Surgical activity}

During the nationwide lockdown, we performed the following surgical procedures, which included acute and subacute emergencies.

diagnosis and treatment of malignant tumors of the head and neck, management of airway emergencies in adults and children, drainage of abscesses of the head and neck, Foreign body removal, emergency nasal debridement and surgeries for the unsafe ear.

Also the number of cases of individual surgeries were compared with the data obtained during the same period in previous year.

Table 1 Triage of various categories of surgeries

Acute emergencies

Subacute emergencies

Nonurgent procedures

(definite need of surgery and long wait may affect the outcome)
Airway obstruction of any kind

Foreign bodies in the aerodigestive tract

Neck trauma with injuries to the vessels and upper aerodigestive tract

Torrential epistaxis

Condition or procedure impending or anticipating airway obstruction

Life-threatening otologic surgery such as intracranial complications of chronic suppurative otitis media (CSOM)

The acute emergency surgery needs to be performed on an as early as possible basis on the same day of presentation within $24 \mathrm{~h}$

Surgery for a complication of rhinosinusitis

Deep neck space infection

Cellulitis, abscess or sepsis not responding to medical therapy

Maxillofacial trauma

Acute facial nerve palsy

Acute mastoiditis

Biopsy for tissue diagnosis in neck

Laryngoscopic laryngeal/hypopharyngeal biopsy or oropharyngeal/nasopharyngeal biopsies for tissue diagnosis

Surgery for benign lesions of larynx not in stridor

These procedures need to be performed within 48-72 hrs

Surgery for cancers of the head and neck

Surgeries for airway tract stenosis or stricture on tracheostomy

Ear foreign bodies not causing pain or vegetative ear foreign bodies

Perilymph fistula

Sinus nasal pathology leading to acute rhinosinusitis

Microlaryngoscopic procedure for lesions causing breathing difficulty without any compromise of the airway

CSF rhinorrhea repair

These procedures need to be performed-within 4-6 weeks of presentation

All other surgeries which can be delayed for 2-3 months
Elective (need of surgery

is there. However, the wait time might not significantly impact the outcome) 
To minimise inadvertent exposure to health care workers risk stratification of the case was based on the level of Aerosol generation during the procedure and level of PPE(Personal Protective Equipment) required for the procedure was decided keeping in mind the shortage of PPE during the lockdown period (Table 2).

All aerosol generating procedure were done in negative pressure operating room.

By assessing the aerosol generation minor neck cases and biopsies were done under local anaesthesia rest were done under general anaesthesia complying with the institution protocol and to prevent agitation by patient and risk to $\mathrm{HCW}$.

Measures were also taken in the operating room, the number of personals operating room were kept as minimal as possible which included an operating surgeon, assisting surgeon (for neck case and skull base procedures), scrub nurse, anaesthetist and anaesthesia technician.

Anaesthetist would thoroughly paralyse and relax the patient before intubation to prevent aerosol generation and immediately after intubation the patient the endotracheal tube is connected to the circuit.

Intubated patients from ICU needing tracheostomy for prolonged intubation the patient would be shifted on a portable ventilator to the operating room and while changing the circuit the endotracheal tube is temporarily clamped and then connected to the new circuit the same is done after the surgery to shift the patient back to the portable ventilator.

For tracheostomy after opening the trachea anaesthetist and the assisting surgeon is asked to move few steps away from table trachea is opened, suction catheter is placed and smaller size cuffed tracheostomy tube is inserted cuff is inflated and then once the anaesthetist is ready to connect the circuit the obturator is removed and tube place confirmed. All these steps are done with brisk movements not wasting any time by the operating surgeon and anaesthetist.

\section{Results}

During the period of march 24th 2020-may 20th 2020 a total of 52 surgeries were performed.

Airway surgeries were 28(53.8\%), deep neck infections $7(13.4 \%)$, malignancies of head and neck 6(11.54\%), Foreign body removal $5(9.6 \%)$, emergency nasal debridement $5(9.6 \%)$ each, surgeries of unsafe ear $1(2 \%)$, elective procedures $0(0 \%)$ (Fig. 1).

When compared to the same period in the previous year ie march $24^{\text {th }} 2019$-may 20th 2019 total of 255 cases were done.

Airway surgeries 38(15.11\%), deep neck infections $6(2.3 \%)$, malignancies of head and neck 33(12.8\%), Foreign body removal $3(1.1 \%)$, emergency nasal debridement $9(3.4 \%)$ each, surgeries of unsafe ear $6(2.3 \%)$, elective procedures 160(62.8\%) (Fig. 2).

Based on the triage of requirement for surgery Acute Emergencies 16 cases(31\%), Subacute emergencies 35(67\%), non urgent 1(2\%) Electives 0(0\%) (Fig. 3).

The risk stratification based on aerosol generation and requirement of PPE no COVID positive patients were operated, while most 43(83\%) were aerosol generating procedures, non aerosol generating surgeries were $8(15 \%)$ and 1(2\%) doubtful AGP (Fig. 4).

\section{Discussion}

SARS-CoV-2 is very infectious, with a control reproduction number that may be as high as 6.47 (95\% CI, 5.71-7.23), which is higher than the SARS transmission number in 2003 [4].

As previously discussed, ENT healthcare providers mainly manage cases related to upper aerodigestive tract and therefore may be subjected to high-risk exposures in different scenarios. With reports of high aerosol generation in operation room while dealing with such cases it is important that workers in ENT department use standard precautions consistently $[5,6,7]$.

Table 2 Risk stratification

\begin{tabular}{llc}
\hline COVID 19 positive & Any surgical procedure & Maximal PPE \\
\hline $\begin{array}{l}\text { Aerosol generating } \\
\text { procedure }\end{array}$ & $\begin{array}{c}\text { COVID 19(Negative/suspect) for surgery of the } \\
\text { aerodigestive tract }\end{array}$ & $\begin{array}{c}\text { N95 mask, face shield, eye cover, long sleeve fluid-resistant gowns, } \\
\text { and gloves }\end{array}$ \\
$\begin{array}{l}\text { Doubtful AGP } \\
\text { COVID 19 (Negative/Suspect) for mastoid } \\
\text { surgery }\end{array}$ & $\begin{array}{c}\text { N95 mask, eye cover, long sleeve fluid-resistant gowns, and gloves, } \\
\text { maximal microscope drape }\end{array}$ \\
$\begin{array}{c}\text { Non Aerosol generating } \\
\text { procedure }\end{array}$ & COVID 19 (Negative/Suspect) for neck surgery & $\begin{array}{c}\text { Surgical mask, eye cover, and gloves } \\
\end{array}$ \\
\hline
\end{tabular}




\section{SURGICAL ACTIVITY DURING THE}

PANDEMIC

$60.00 \%$

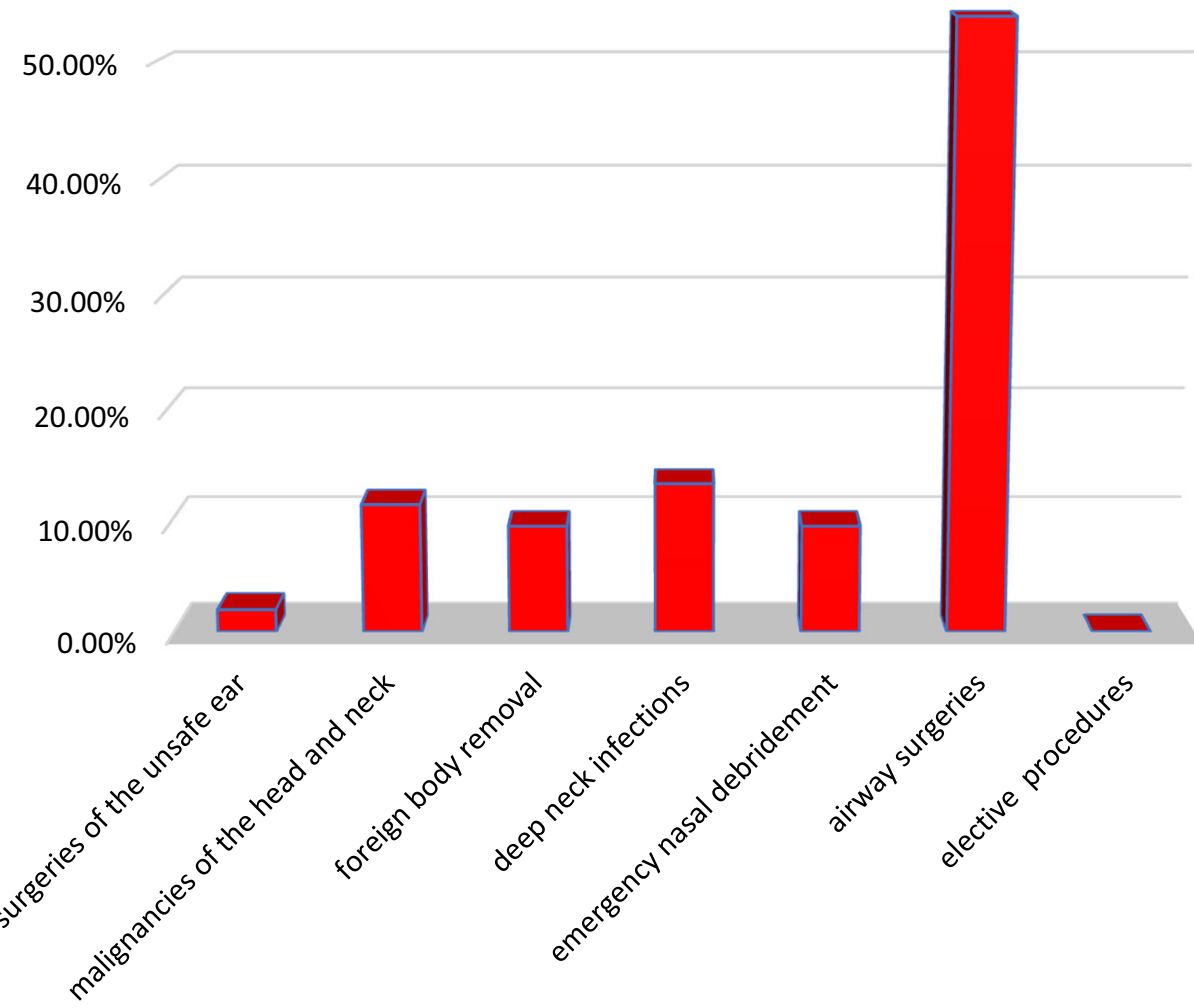

Fig. 1 Distribution of surgeries done during COVID 19 lockdown

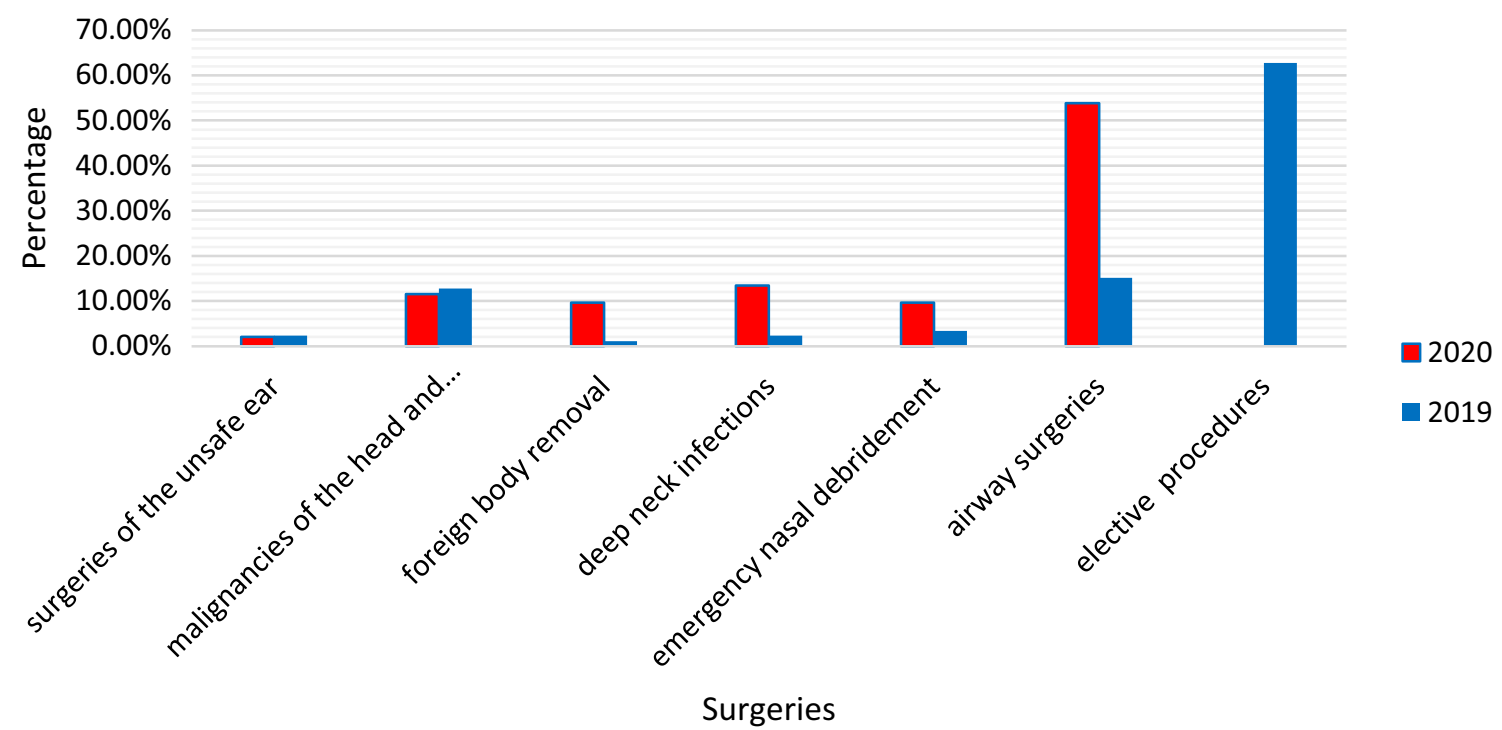

Fig. 2 Comparing the percentage of surgeries done during the lockdown vs that during the same period in the previous year

As many are asymptomatic carriers, a strict triage system is applied to maintain a high index of suspicion so that no accidental exposure occurs to the HCW. This involves enquiring about travel history, stratification of containment areas based on number of positive cases which is issued by the government body on daily basis [8]. 


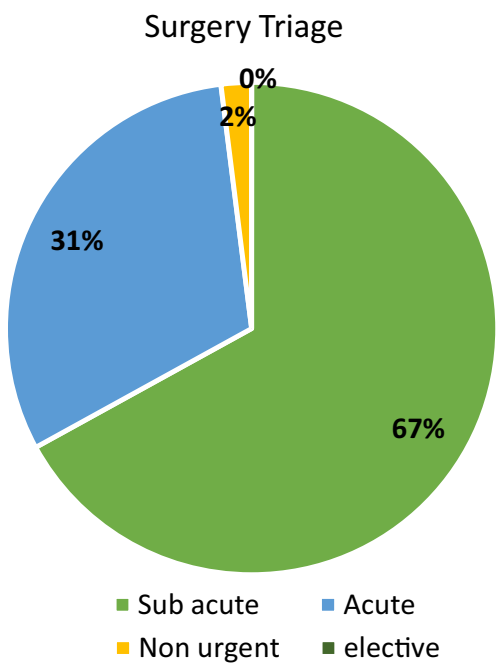

Fig. 3 Case distribution according to surgery triage

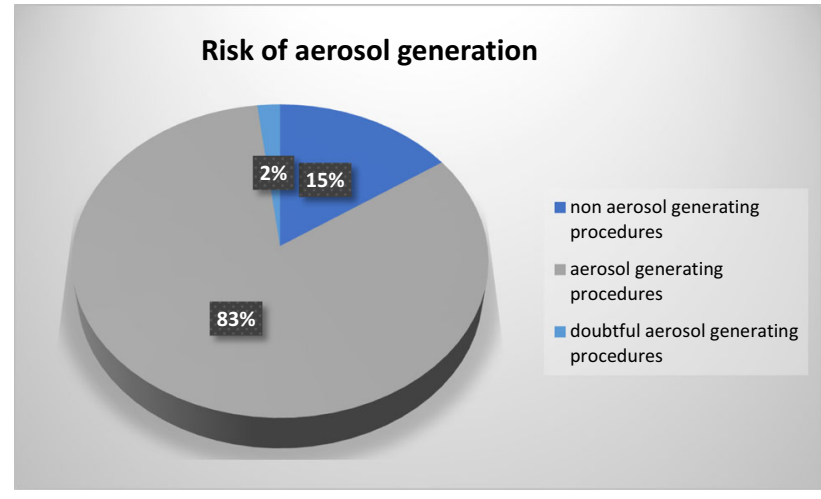

Fig. 4 Risk stratification

The risk stratification guidelines and triage strategy was employed by compiling multiple guidelines regarding COVID 19 ie., ENTUK, American Academy of Otolaryngology and Head and Neck Surgery (AAOHNS), The American Laryngological, Rhinological and Otological Society, ENT Canada, National Health Service (NHS), Center for Disease Control (CDC) and Indian Council Of Medical Research (ICMR) [9, 10, 11].

The utilization of PPE in second-level protection(yellow) and third-level protection(red) here roughly corresponds to standard PPE and enhanced PPE, respectively, as described by the Centre for disease control and prevention(CDC) [12].

Rigorous implementation and adherence of these strategies were employed to ensure that the diagnostic and therapeutic procedures were performed promptly in necessary cases.

There was significant increase in adult patients who needed surgery for deep neck infection; this maybe directly related to patients presenting late to hospital with advanced surgical pathology often due to a fear of hospital admission during this pandemic or due to a reduction in outpatient activity. Similar findings were observed in other studies as well [13].

Draining a neck abscess is not high AGP but owing to the fact that many presented late to the hospital, most of these patients had to undergo tracheostomy due to difficult or failed Endotracheal intubation [14].

There are reports of high aerosol generation during percutaneous tracheostomy and risk of exposure to other patients in intensive units while performing the procedure bed-side. Hence, while avoiding a bed-side procedure, significant number of open tracheostomies in OR were performed on non-COVID critical patients in intensive unit who otherwise needed prolonged intubation $[15,16]$.

There were no COVID positive patients who needed tracheostomy as the mortality rate once a patient goes into severe or critical ARDS is as high as $70 \%$, which may argue against proceeding with tracheostomy on COVID patients. Rather, tracheotomy should only be used in specific situations such as airway obstruction where the potential for successful extubation is otherwise compromised or in circumstances where tracheotomy placement might positively affect a patient's potential for successful weaning of minimal ventilatory support $[9,17,18,19]$.

A number of other Aerosol Generating Procedures were performed during this period which includes endoscopic removal of foreign body from nose, Endoscopic skull base surgery for JNA, Micro laryngeal Posterior cordotomy for bilateral abductor palsy, laryngeal/ hypopharyngeal biopsy and oral biopsy. To prevent further risk of aerosol generation instruments like $\mathrm{CO} 2$ laser, Electrocautry, high speed rotating devices were not used and hence conventional techniques were employed [20].

There are incomplete evidences of possible risk of exposure while performing a mastoid surgeries as it is continuation of the respiratory epithelium from eustachian tube but to prevent any inadvertent exposure such cases who needed surgical treatment and semi emergency cases like facial nerve palsy due to complication of CSOM, mastoiditis, skull base osteomyelitis were observed in the hospital with protocol(changed) to treat the middle ear infection with aggressive medical line of management and observation, ensuring for the time of active phase of the viral infection to settle down then planned for surgery $[20,21]$.

\section{Conclusion}

With the COVID 19 pandemic a drastic change in the surgical activity was observed with reduced numbers and increase in complicated and ICU tracheostomy for 
prolonged intubation. With adequate precautions by risk stratification and strict triage put in place the risk to the health care workers can be avoided while providing essential services.

\section{References}

1. Mackenzie JS, Smith DW (2020) COVID-19: a novel zoonotic disease caused by a coronavirus from China: what we know and what we don't. Microbiol Aust. https://doi.org/10.1071/MA20013

2. Zou L, Ruan F, Huang M et al (2020) SARS-CoV-2 viral load in upper respiratory specimens of infected patients. N Engl J Med 382(12):1177-1179. https://doi.org/10.1056/NEJMc2001737

3. Liu Y, Liao W, Wan L, Xiang T, Zhang W (2020) Correlation between relative nasopharyngeal virus RNA load and lymphocyte count disease severity in patients with COVID19. Viral Immunol. https://doi.org/10.1089/vim.2020.0062

4. Tang B, Wang X, Li Q et al (2020) Estimation of the transmission risk of the 2019-nCoV and its implication for public health interventions. J Clin Med 9(2):462. https://doi.org/10.3390/jcm90 20462

5. Kulcsar MA, Montenegro FL, Arap SS, Tavares MR, Kowalski LP (2020) High risk of COVID-19 infection for head and neck surgeons. Int Arch Otorhinolaryngol 24(2):e129-e130. https://doi.org/10.1055/s-0040-1709725

6. Patel ZM, Hwang PH, Nayak JV, et al. Stanford university school of medicine. Departments of otolaryngology-H\&N surgery and neurosurgery. Available from: https://www.enttoday.org/article/ otolaryngologists-may-contract-covid-19-during-surgery/

7. Ran L, Chen X, Wang Y, Wu W, Zhang L, Tan X (2020) Risk factors of healthcare workers with corona virus disease 2019: a retro- spective cohort study in a designated hospital of Wuhan in China. Clin Infect Dis. https://doi.org/10.1093/cid/ciaa287

8. Updated containment plan for large outbreaks novel coronavirus disease 2019 (COVID-19) Ministry of Health and Family Welfare Government of India https://www.google.com/url?sa=t\&rct= $\mathrm{j} \& \mathrm{q}=\&$ esrc $=\mathrm{s} \&$ source $=$ web $\& \mathrm{~cd}=\& \mathrm{cad}=\mathrm{rja} \&$ uact $=8 \& \mathrm{ved}=2 \mathrm{ahUKE}$ wjr5dCNO_fpAhWx63MBHUCkCmgQFjACegQIAhAB\&url= https $\% 3 \mathrm{~A} \% 2 \mathrm{~F} \% 2 \mathrm{Fwww} . \mathrm{mohfw}$.gov.in\%2Fpdf\%2FUpdatedCon tainmentPlanforLargeOutbreaksofCOVID19Version3.0.pdf\&usg =AOvVaw0nTWKP9fXApF1pQ6uR7ZgZ

9. ENT UK (2020) Guidance for surgical tracheostomy and tracheost- omy tube change during the COVID-19 pandemic. https://www.entuk.org/tracheostomy-guidance-during-covid-19pandemic. Accessed March 27, 2020

10. Boccalatte LA, Larraaga JJ, Perez Raffo GM, Teijido CA, Garca Fornari G, Staneloni MI, Figari MF (2020) Brief guideline for the prevention of COVID-19 infection in head and neck and otolaryngology surgeons. Am J otolaryngol. https://doi.org/10.1016/ j.amjoto.2020.102484

11. Vukkadala N, Qian ZJ, Holsinger FC, Patel ZM, Rosenthal E (2020) COVID-19 and the Otolaryngologist: preliminary evidence-based review. Laryngoscope. https://doi.org/10.1002/ lary. 28672

12. Infection control guidance for healthcare professionals about coronavirus (COVID-19) https://www.cdc.gov/coronavirus/2 019-ncov/hcp/infection-control.html

13. Ellis R, Hay-David A, Brennan PA (2020) Operating during the COVID-19 pandemic: how to reduce medical error. Br J Oral Maxillofac Surg 58(5):577-580. https://doi.org/10.1016/j.bjoms. 2020.04.002

14. Ovassapian A, Tuncbilek M, Weitzel EK et al (2005) Airway management in adult patients with deep neck infections: a case series and review of the literature. Anesth Analg 100:585-589

15. Tien HC, Chughtai T, Jogeklar A, Cooper AB, Brenneman F (2005) Elective and emergency surgery in patients with severe acute respiratory syndrome (SARS). Can J Surg 48:71-74

16. Chee VW, Khoo ML, Lee SF, Lai YC, Chin NM (2004) Infection control measures for operative procedures in severe acute respiratory syndrome-related patients. Anesthesiology 100:1394-1398

17. World Health Organization. Coronavirus disease 2019 (COVID19), situation report 47. Available at: https://www.who.int/docs/ default-source/coronaviruse/situation-reports/20200307-sitrep-47covid-19.pdf. Accessed on 1 March 2020

18. Yang X, Yu Y, Xu J, Shu H, Xia J, Liu H et al (2020) Clinical course and outcomes of critically ill patients with SARS-CoV-2 pneumonia in Wuhan, China: a single-centered, retrospective, observational study. Lancet Respir Med. https://doi.org/10.1016/ S2213-2600(20)30079-5

19. Goh KJ, Choong MC, Cheong EH et al (2020) Rapid progression to acute respiratory distress syndrome: review of current understanding of critical illness from COVID-19 infection. Ann Acad Med Singap 49(3):108-118

20. Thamboo A, Lea J, Sommer DD et al (2020) Clinical evidence based review and recommendations of aerosol generating medical procedures in otolaryngology-head and neck surgery during the COVID-19 pandemic. J Otolaryngol Head Neck Surg 49:28. https://doi.org/10.1186/s40463-020-00425-6

21. Chen JX, Workman AD, Chari DA et al (2020) Demonstration and mitigation of aerosol and particle dispersion during mastoidectomy relevant to the COVID-19 era. Otol Neurotol. https://doi.org/10.1097/MAO.0000000000002765

Publisher's Note Springer Nature remains neutral with regard to jurisdictional claims in published maps and institutional affiliations. 